\title{
Relation of Vitamin D Receptor Gene (VDR) Polymorphism FOK-I in Subtype of Hashimoto's Thyroiditis
}

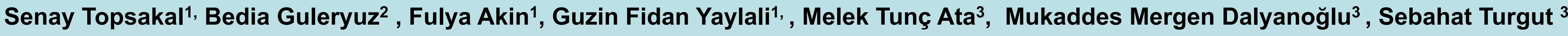 \\ ${ }^{1}$ Department of Endocrinology and Metabolism, Faculty of Medicine, Pamukkale University, Kinikli Campus, Denizli, 20070, Turkey \\ 2Department of Internal Medicine, Faculty of Medicine, Pamukkale University, Kinikli Campus, Denizli, 20070, Turkey \\ ${ }^{3}$ Department of Physiology, Faculty of Medicine, Pamukkale University, Kinikli Campus, Denizli, 20070, Turkey
}

\section{Objectives:}

\section{Methods:}

Results:

Conclusions.

VDR gene polymorphisms and vitamin D levels have been associated with various autoimmune diseases such as Hashimoto's thyroiditis (HT) (1,2)More than 30 gene polymorphisms are found in VDR gene.(3) The most common 4 types of polymorphisms studied in autoimmune disease are FOK-I (ekzon 2), BSM1 (intron 8), APA-1 (intron 8) and TAQ-I (ekzon 9).(4)

The aim of this study is to investigate the association between VDR FOK-I gene polymorphism and Hashimoto's thyroiditis subtypes.

We performed a case-control study that included 139 cases with HT (50 euthyroid, 50 subclinical hypothyroid, 39 overt hypothyroid patients) and 50 healthy control. Subjects were recruited from Endocrinology Clinic. VDR FOK-I gene polymorphisms were examined using a polymerase chain reaction (PCR). HT cases were classified into three subgroups according to their thyroid function status: Euthyroid patients (Group-1) ,subclinical hypothyroid patients (group-2) Evident hypothyroid patients (Group-3).

Table-1 The FOK-I genotype distribution in groups.

\section{EUTHYROID HT \\ (GROUP-1)}

$n(\%)$

24(49)

18(36.7)

$7(14.3)$

\section{SUBCLINICAL HT \\ (GROUP-2)}

$n(\%)$
EVIDENT HT

(GROUP-3)

$n(\%)$
CONTROL

$\mathrm{n}(\%)$

\section{FOK-I}

FF

Ff

ff

\begin{tabular}{ll} 
FF & $24(49)$ \\
\hline Ff & $18(36.7)$ \\
ff & $7(14.3)$
\end{tabular}

There were no statistically significant differences observed in all Hashim
with the control group. No statistically significant difference was seen
hypothyroid, evident hypothyroid groups and the control group.(Table-1)

This study showed that VDR FOK-I gene polymorphism did not effect the occurrence of the HT. In a study about VDR genotype distribution in Turkey reported the frequency of FF genotype as $55 \%$, Ff genotype as $36 \%$ and ff genotype as $9 \%$ in Fokl gene. (5). This result is supported our study.

1-Ming Feng, HuaLi, Su-FangChen, Wei-FangLi, Fang-Bin Zhang.Polymorphisms in the vitamin $D$ receptor gene and risk of autoimmune thyroid diseases : a meta-analysis Endocrine (2013) 43:318-326

2-F.Baeke, T.Takiishi, H.Korf, C.Gysemans, C.Mathieu, Vitamin D: modulator of the immune system. Curr.Opin. Pharmacol.10(4), 482-496 (2010)

3-A.L.Ponsonby, A.Pezie, J.Ellis, R.Marley ,F.Cameron, J.Carlin, T.Dwyer, Variation in associations between allelie variants of the vitamin d receptor gene and onset of type 1 diabetes mellitus by ambient winter ultraviolet radiation levels: a meta regression analysis. Am.J.Epidemiol 168(4), 358-365(2008)

-4-Yazici D, Yavuz D, Tarcin O, Sancak S, Deyneli O, Akalin S. Vitamin D receptor gene Apal, Taql, Fokl and Bsml polymorphisms in a group of Turkish patients with Hashimoto's thyroiditis.MinervaEndocrinol. 2013 Jun;38(2):195-201

5-Ramos-Lopez E, Kurylowicz A, Bednarczuk T, Paunkovic J, Seidl C, Badenhoop K. Vitamin D receptor polymorphisms are associated with Graves' disease in Germanand Polish but not in Serbian patients. Thyroid. 2005 Oct; 15(10):1125-30 